\title{
21st Century Genetics: Mass Spectrometry of Yeast Telomerase
}

\author{
KaH Wai Lin AND Virginia A. ZaKian \\ Department of Molecular Biology, Lewis Thomas Labs, Princeton University, \\ Princeton, New Jersey 08544 \\ Correspondence: vzakian@princeton.edu
}

\begin{abstract}
Telomerase is a specialized reverse transcriptase that maintains the ends of chromosomes in almost all eukaryotes. The core of telomerase consists of telomerase RNA and the reverse transcriptase that uses a short segment without the RNA to template the addition of telomeric repeats. In addition, one or more accessory proteins are required for telomerase action in vivo. The beststudied accessory protein is Est1, which is conserved from yeasts to humans. In budding yeast, Est1 has two critical in vivo functions: By interaction with Cdc13, a telomere-binding protein, it recruits telomerase to telomeres, and it also increases telomerase activity. Although budding yeast telomerase is highly regulated by the cell cycle, Est 1 is the only telomerase subunit whose abundance is cell cycle-regulated. Close to 400 yeast genes are reported to affect telomere length, although the specific function of most of them is unknown. With the goal of identifying novel telomerase regulators by mass spectrometry, we developed methods for purifying yeast telomerase and its associated proteins. We summarize the methods we used and describe the experiments that show that four telomerase-associated proteins identified by mass spectrometry, none of which had been linked previously to telomeres, affect telomere length and cell cycle regulation of telomerase by controlling Est1 abundance.
\end{abstract}

Telomeres, the DNA-protein structures at the ends of eukaryotic chromosomes, are usually elongated by a telomere-dedicated reverse transcriptase called telomerase. The catalytic core of telomerase consists of an RNA component (called TLC1 in budding yeast) that serves as the template for elongating the G-rich strand of telomeric DNA and the catalytic reverse transcriptase subunit (Est2 in budding yeast; TERT in higher cells). In addition, the telomerase holoenzyme contains one or more speciesspecific accessory proteins. For example, budding yeast has two such subunits, Est1, which is found from yeasts to mammals, and Est3, which is not evolutionarily conserved (although in mammals its function may be performed by the structurally related TPP1 protein [Lee et al. 2008; Yu et al. 2008]). In budding yeast, all four of these subunits-TLC1, Est1, -2, and -3-are essential for telomerase action in vivo (for review, see Wellinger and Zakian 2012).

As with many cellular processes, yeast genes affecting telomeres were first identified in genetic screens, including all four of the essential telomerase subunits, Est1, -2, -3 , and TLC1 RNA (Lundblad and Szostak 1989; Singer and Gottschling 1994; Lendvay et al. 1996). Genes affecting the telomere length were also identified by screening the deletion collection of nonessential genes and the DAmP collection of essential genes (Askree et al. 2004; Gatbonton et al. 2006; Ungar et al. 2009). As a result of these combined efforts, approximately $370 \mathrm{Sc}$ genes are reported to affect the telomere length. However, the mechanism of action of most of these genes is not known, and many probably act indirectly. Moreover, the two groups that examined the deletion collection identified mostly nonoverlapping gene sets, raising concerns about the reliability of these screens.

Inspired by the success of mass spectrometry (MS) to identify novel components of telomerase in both the ciliate Tetrahymena and human tumor cells, we reasoned that MS would allow us to focus on the subset of yeast proteins that affect the telomere length by direct effects on telomerase. MS of purified Tetrahymena telomerase identified multiple previously unknown telomere proteins, such as p65, a telomerase RNA-binding protein required for wild-type levels of telomerase RNA and a trimeric complex, p75-p45-p19, that is related to the budding yeast CST complex (CTC1-STN1-TEN1) and affects telomere structure and replication (Witkin and Collins 2004; Witkin et al. 2007; Min and Collins 2009; Jiang et al. 2015; Wan et al. 2015). MS of telomerase from human cells identified both telomerase RNAbinding proteins and ATPases such as pontin and reptin that affect the telomere length (Fu and Collins 2007; Venteicher et al. 2008). TCAB1, another telomerase-associated RNA-binding protein discovered by MS, controls intracellular trafficking of human telomerase (Venteicher et al. 2009).

In Tetrahymena and immortalized human cultured cells, an MS strategy is facilitated by the high levels of telomerase in these cells. For example, Tetrahymena telomerase is isolated from a specific developmental stage, postmating cells, that undergo massive telomerase-mediated new telomere formation (Witkin and Collins 2004; Witkin et al. 2007). In contrast to these systems, telomerase is present in low amounts in most organisms, making it a challenge for MS approaches. Telomerase abundance has been best 
documented in budding yeast where there are about half the number of telomerase complexes as telomeres in post$\mathrm{S}$ phase cells, when telomerase acts. The least abundant subunit is TLC1 RNA, estimated at approximately 30 copies per cell (Mozdy and Cech 2006). The protein subunits of budding yeast telomerase are also present in low amounts. Asynchronous yeast cells contain approximately 70,40 , and 80 molecules of, respectively, Est1, -2, and -3 (Tuzon et al. 2011; Wu and Zakian 2011). In yeast, where telomerase is expressed constitutively, its level is about what is needed to maintain wild-type telomere length. For example, when the amount of telomerase RNA is reduced, as in heterozygous $t l c 1 \Delta / T L C 1$ diploid cells, telomeres are shorter than in wild-type cells; that is, the TLC1 gene is haplo-insufficient (Mozdy and Cech 2006). In humans, telomerase is not expressed in most somatic cells. Even in human stem cells, where it is expressed, telomerase expression is quite low as heterozygous alleles of both TERT and telomerase RNA lead to short telomeres and diseases characterized by stem cell failure and reduced life span (reviewed in Armanios and Blackburn 2013).

As in many organisms, the ability of budding yeast telomerase to lengthen telomeres is cell cycle-regulated. Telomerase-mediated telomere elongation is not detected in $G_{1}$ or early $S$ phase yeast cells but rather is limited to late in the cell cycle (Diede and Gottschling 1999; Marcand et al. 2000). Of the four key telomerase subunits, Est1 is the only one whose abundance is cell cycle-regulated (Taggart et al. 2002). Est1 is present in approximately 20 molecules per cell in $G_{1}$ phase, when telomerase is not active, and approximately 120 molecules per cell in $\mathrm{G}_{2} / \mathrm{M}$ phase, when it is active ( $\mathrm{Wu}$ and Zakian 2011). Est1 regulation is imposed in part by regulated degradation of its mRNA (Larose et al. 2007) and in part by proteosome-mediated Est1 degradation (Osterhage et al. 2006; Ferguson et al. 2013). Est1 interacts directly with both TLC1 RNA (Seto et al. 2002) and Est3 (Osterhage et al. 2006; Tuzon et al. 2011), and both interactions are critical for telomerase action. In addition, a direct interaction between Est 1 and the Cdc13 component of the CST complex, which binds the single-strand Gtails that mark the very end of the chromosome, is critical for recruitment of telomerase to DNA ends in vivo and in vitro (Bianchi et al. 2004; Wu and Zakian 2011). The Est1-Est3 interaction is essential for Est3 incorporation into the holoenzyme and for its recruitment to telomeres (Osterhage et al. 2006; Tuzon et al. 2011).

Given that Est1 is required for telomerase recruitment and for an activation step, which is likely the recruitment of Est3, cell cycle-regulated abundance of Est1 is theoretically sufficient to explain why the telomerase holoenzyme acts only in late $\mathrm{S}$ phase. However, even if Est1 is expressed at high levels in $G_{1}$ phase, which results in formation of the holoenzyme, telomerase is still unable to lengthen telomeres (Osterhage et al. 2006). We speculate that this inactivity reflects the lack of an appropriate DNA substrate for the complex. Although yeast telomeres bear short (5-15-nt) $\mathrm{TG}_{1-3}$ extensions, often called Gtails, throughout most of the cell cycle, longer G-tails $(20-25-n t)$ are generated late in the cell cycle (Wellinger et al. 1993; Larrivée and Wellinger 2004; Soudet and Teixeira 2014). Even though long G-tails are detected at the time when telomerase acts, their appearance does not require telomerase (Wellinger et al. 1996). Rather, long G-tails are generated by cell cycle-regulated Cstrand degradation (Huertas et al. 2008; Bonetti et al. 2009).

The cell cycle-regulated appearance of long G-tails is cyclin dependent kinase (Cdk)-dependent (Frank et al. 2006; Vodenicharov and Wellinger 2006) and occurs mainly on the newly synthesized leading strand (Soudet and Teixeira 2014). The Mre11-Rad50-Xrs2 complex recruits the ATM-like kinase Tel1 to telomeres, which phosphorylates one or more substrates, and these modified proteins promote telomerase recruitment to telomeres (Sabourin et al. 2007; McGee et al. 2010). As the Mre11 complex binds preferentially to newly made leading strand telomeres (Faure et al. 2010), long G-tails are probably the preferred telomerase substrate. Thus, in addition to increased Est1, long G-tails and probably Cdkmediated phosphorylation of one or more proteins, such as $\mathrm{Cdc} 13$ (Li et al. 2009), all contribute to telomerase being cell cycle-regulated.

Here we describe our success in purifying yeast telomerase for MS analysis. These efforts identified more than 100 telomerase-interacting proteins, of which $\sim 70 \%$ had not been implicated previously in telomerase biology. So far, we have tested eight of the novel telomerase-associated proteins, and seven of these affect telomere length. We describe the methods that enabled us to obtain biochemically useful amounts of telomerase, identify a novel hetero-trimeric complex that regulates telomerase abundance, and speculate on why these studies did not identify many differences in telomerase-associated proteins in $\mathrm{G}_{1}$ versus $\mathrm{G}_{2}$ phase cells. (For more details of results and methods, see Lin et al. 2015.)

\section{METHODS FOR ISOLATING YEAST TELOMERASE}

We were unable to isolate telomerase until we overexpressed each of the four essential telomerase subunits (TLC1 RNA, Est1, Est2, and Est3) from the strong and inducible GAL1 promoter. Est 1 and Est 2 were expressed as GFP fusions, which is critical for the method we used to affinity purify telomerase. (Est3 was not expressed as a GFP fusion because doing so reduces its activity as inferred by short telomeres.) Based on levels of TLC1 RNA, this approach resulted in about a 10-fold increase in telomerase. Cells overexpressing telomerase have normal growth rates and cell cycle progression profiles, but their telomeres are hyperelongated, suggesting that the increase in telomerase increases telomerase action (Lin et al. 2015).

Isolation of telomerase was achieved by immunoprecipitation with a high-titer anti-GFP serum developed in the laboratory of Dr. Ileana Cristea (Princeton University) (Cristea et al. 2005). Another key to success was identifying conditions for efficient solubilization of the telo- 
merase complex. We isolated telomerase from $\mathrm{G}_{1}$ arrested cells (telomerase inactive) and $\mathrm{G}_{2} / \mathrm{M}$ arrested cells (telomerase active). As a control, we fused the SV40 nuclear localization signal to GFP. We discarded proteins in the control immunoprecipitates from consideration.

\section{PROTEINS ASSOCIATED WITH TELOMERASE}

We determined the significance of the interactions of proteins that immunoprecipitated with telomerase using the SAINT algorithm (Significance Analysis of INTeractome), which considers the number of spectral counts in both experimental and control isolations, the frequency of detection across biological replicates, and protein length (Choi et al. 2011). Using a stringent SAINT score cutoff of 0.8 , we identified 89 telomerase-associated proteins from $\mathrm{G}_{1}$ phase and 72 from $\mathrm{G}_{2} / \mathrm{M}$ phase cells. About $30 \%$ (37 proteins from both $\mathrm{G}_{1}$ and $\mathrm{G}_{2} / \mathrm{M}$ phases) of the proteins are still telomerase-associated after DNase I treatment of the extracts. Most proteins (58 of 74) were present with high SAINT scores in both $G_{1}$ and $G_{2} / M$ phase isolations (Lin et al. 2015).

As expected, Est1 and -2 were among the most abundant proteins in the immunoprecipitate, as was Est3, even though Est3 was not GFP-tagged. All seven members of the Sm complex were also telomerase-associated. This result was expected as two members of the heptameric Sm complex, Smd1 and Smd3, have been shown previously to bind TLC1 in vivo (Seto et al. 1999). As noted above, previous genetic analyses link almost 400 genes to effects on telomere length, and $30 \%$ of the telomeraseassociated proteins in our isolations fell into this group, almost fourfold higher than the fraction of yeast genes reported to affect telomere length. As all of the known telomerase subunits and many proteins linked previously to telomerase were present in our samples, we conclude that the multiprotein complex we identified is biologically relevant. We are even more encouraged that the majority of proteins in our samples have not been linked previously to telomerase and are candidates for novel telomerase regulators (Lin et al. 2015).

\section{THE TELOMERASE-ASSOCIATED Cdc48 COMPLEX IS A NOVEL REGULATOR OF TELOMERE LENGTH}

Thirty-four of the proteins identified in our MS analyses are linked to proteolysis. These proteins include $\mathrm{Cdc} 48$, an $\mathrm{AAA}+\mathrm{ATPase}$ that is the catalytic subunit of several protein complexes. In addition, three proteins that associate with $\mathrm{Cdc} 48$ - Npl4, Ufd1, and Shp1-were identified. All four of these proteins have the highest possible SAINT score (1.0) in both $\mathrm{G}_{1}$ and $\mathrm{G}_{2} / \mathrm{M}$ phase, indicating that their association with telomerase is authentic. Consistent with this interpretation, Est1 in present in immunoprecipitations of $\mathrm{Cdc} 48$ in cells that express wild-type levels of telomerase (Lin et al. 2015).
Cdc48 complexes, which are highly conserved in eukaryotes, were first identified because of their role in targeting misfolded proteins from the endoplasmic reticulum to the proteosome for degradation. Subsequent studies in diverse organisms revealed that these complexes function in a wide range of cytoplasmic and nuclear events. However, Cdc48 complexes had not been linked previously to telomerase in any organism. Whereas Cdc48 is the catalytic subunit, the other subunits in Cdc48 complexes recognize and bind ubiquinated proteins. The substrates of Cdc48 complexes are typically themselves subunits of multiprotein complexes. After the Ub-binding subunits in the Cdc48 complex bind the substrate, Cdc48 uses its ATPase activity to remove the substrate from the multiprotein complex. In most but not all cases, the removed subunit is then delivered to the proteosome for degradation, and the multiprotein complex from which the target protein was removed falls apart.

Shp1 and Np14/Ufd1 are found in distinct Cdc48 complexes. Because Shp1 is implicated mainly in membrane fusion (Schuberth et al. 2004), we focused on the Cdc48Np14-Ufd1 complex. If this complex regulates telomerase, we anticipated that its depletion would impact the telomere length. As CDC48, NPL4, and UFD1 are all essential genes, we used temperature-sensitive alleles. Even at permissive temperatures, $c d c 48-3$ cells have telomeres that are $\sim 40$ bp shorter than the $\sim 300$ bp telomeres in an otherwise isogenic wild-type control strain. This short telomere phenotype is rescued by introducing a plasmid-borne copy of CDC48 into the strain, showing that short telomeres are due to limited $\mathrm{Cdc} 48$. In addition, npl4-1, but not ufd1-2, cells have short telomeres (Lin et al. 2015).

The effects of Cdc48 depletion on the telomere length suggest that the Cdc48 complex is a positive regulator of telomerase. Given that Cdc48 complexes usually target proteins for degradation, we used western blot analysis to identify telomere proteins whose abundance is Cdc48dependent. We tested six proteins that affect telomerase activity: Est1 and Est2 (two of the three essential protein subunits of telomerase), Pif1 (a DNA helicase that removes telomerase from telomeres in vivo and in vitro (Boule et al. 2005), two telomere-binding proteins that function in telomerase recruitment (Cdc13 and Yku80) (Bianchi et al. 2004; Fisher et al. 2004; Wu and Zakian 2011), and Rap1 (a duplex telomere binding protein that recruits Rif1 and Rif2, two negative regulators of telomerase, to telomeres [Hardy et al. 1992; Wotton and Shore 1997; Teng et al. 2000]). We examined the abundance of each protein in wild-type and $c d c 48-3$ cells at both permissive and semipermissive temperatures.

Est1 is the only one of the six proteins we tested whose level is affected by reduced Cdc48. Compared to wild cells, Est 1 is 40 times more abundant in $c d c 48-3$ cells. Est1 levels are similarly elevated in $n p l 4-1$ and $u f d 1-2$ cells. In addition, Est1 levels are no longer cell cycleregulated in $c d c 48-3$ cells. Elevated levels of Est1 in Cdc48 depleted cells are the expected result if the Cdc48-Np14-Ufd1 complex targets Est1 for degradation (Lin et al. 2015). 
By several criteria, Est1 is an activator of telomerase (for review, see Wellinger and Zakian 2012). For example, overexpression of Est1 in wild-type cells leads to telomere lengthening (Zhou et al. 2000). Thus, we were surprised that $c d c 48-3$ cells have short telomeres despite containing a large excess of Est 1 . We showed that excess Est1 does not limit telomere length by titrating its interacting partner Est3 from telomeres, as overexpressing Est3 does not ameliorate the short telomere phenotype of $c d c 48-3$ cells. We reasoned that the Est1 that accumulates in $c d c 48-3$ cells must be defective in activation and hence different biochemically from the Est1 in wild-type cells. Given that the Cdc48 complex targets ubiquinated proteins for degradation, the obvious possibility is that Est1 is ubiquinated in Cdc48-depleted cells, and Est1$\mathrm{Ub}$ is less able to activate telomerase (Lin et al. 2015).

To determine if Est 1 is ubiquinated, we expressed His6tagged Ubiquitin (Ub) in $c d c 48-3$ and wild-type cells that also express Myc-tagged Est1. We isolated proteins bearing His6-Ub by passing cell extracts over a Ni column, which retains His6-labeled proteins. The retained proteins were eluted, separated on gels, and analyzed by both antiHis and anti-Myc westerns. Est 1 is present in both extracts. Although Cdc48 complexes are often described as recognizing polyubiquinated proteins, only monoubiquinated Est 1 is detected in these experiments. This finding is not unprecedented as Cdc48 complexes extract monoubiquinated transcription factors from both yeast and mammalian chromatin (Ndoja et al. 2014). Although Est 1 ubiquination is detectable in $c d c 48-3$ and wild-type extracts, the fraction of Est $1-\mathrm{Ub}$ compared to total Est 1 is approximately twofold higher in extracts from $c d c 48-3$ cells compared to wild-type cells (Lin et al. 2015).

\section{THE TELOMERASE-ASSOCIATED UFD4 AFFECTS TELOMERE LENGTH AND Est1 ABUNDANCE}

The demonstration that Est1 is cell cycle-regulated by a proteosome-dependent process (Taggart et al. 2002; Osterhage et al. 2006) led us and others to look for Est 1 ubiquination. However, Est1-Ub is difficult to detect, probably because Est1 is not abundant in wild-type cells. Indeed, even when 10 times as much extract is used for wild-type versus $c d c 48-3$ cells, Est1-Ub is barely detectable in wild-type extracts, although it is easily seen in the mutant extract (Lin et al. 2015). There are hints from earlier studies that the E3 Ub ligase, Cdh1, affects telomere length (Ferguson et al. 2013), but because the authors were unable to detect Est1-Ub, it was unclear whether Cdh1 affects telomeres by modifying Est1.

There are more than 80 E3 ligases in yeast. To identify the E3 Ub ligase that modifies Est1, we tested the three E3 Ub ligases that we telomerase-associated by MS analysis: Ufd4, Tom1, and Ubr1. We reasoned that mutations in the E3 ligase that modifies Est1 should result in more Est 1 and longer telomeres in both wild-type and $c d c 48-3$ cells. Deletion of UFD4 but not that of $C D H 1$ nor either of the two other telomerase-associated E3 ligases has these effects. The fact that telomeres increase in length in both wild-type and $c d c 48-3$ cells provides further support for the activation role of Est1 and for the hypothesis that Est1$\mathrm{Ub}$ is less able to carry out this function (Lin et al. 2015).

\section{THE COMPOSITION OF TELOMERASE IS NOT DRAMATICALLY DIFFERENT IN $\mathbf{G}_{1}$ VERSUS G 2 /M PHASE CELLS}

MS identified a handful of proteins that are telomeraseassociated only in $\mathrm{G}_{1}$ phase (telomerase inactive) or only in $\mathrm{G}_{2} / \mathrm{M}$ phase (telomerase active). One of the more interesting (or at least unexpected) of these is Sme1, one of the seven Sm proteins that bind not only telomerase RNA but also pre-mRNAs. The seven Sm proteins form a ring that encircles the RNA to which they bind. Thus, it is surprising that Sme1 is telomerase-associated in $\mathrm{G}_{1}$ but not $G_{2} / M$ phase, whereas the other six Sm proteins are telomerase-associated in both $G_{1}$ and $G_{2}$ phase. Other proteins are associated with both $\mathrm{G}_{1}$ and $\mathrm{G}_{2} / \mathrm{M}$ phase telomerase but are more abundant in one of the two phases. For example, proteins with roles in proteolysis tend to be more abundant in $\mathrm{G}_{1}$ phase telomerase, whereas chromatin proteins are enriched to a greater extent in $\mathrm{G}_{2} / \mathrm{M}$ telomerase (Lin et al. 2015).

Despite these examples, most telomerase-associated proteins are present in both $\mathrm{G}_{1}$ and $\mathrm{G}_{2} / \mathrm{M}$ phase cells. Perhaps, overexpression of telomerase masks some interactions that occur normally in only one of the two cell cycle phases. Alternatively (or in addition), the events that limit telomerase action to late $S / G_{2}$ phase may not impact the composition of the holoenzyme. For example, if, as we suggest, long G-tails are the in vivo substrate for telomerase, their cell cycle occurrence (in combination with Est1 regulation) can explain why telomerase action is cell cycle-dependent (Wellinger et al. 1993). This view is supported by the inability of telomerase to lengthen telomeres when the holoenzyme is assembled in $\mathrm{G}_{1}$ phase by forced expression of Est1 (Osterhage et al. 2006). Another possibility is that posttranslational modification of telomerase subunits or telomerase regulators contributes to cell cycle regulation. For example, Cdc13, the G-tail binding subunit of CST, is phosphorylated by Cdk1 late in the cell cycle, and this modification increases its ability to interact with Est1 to recruit telomerase to telomeres ( $\mathrm{Li}$ et al. 2009). Other telomerase regulators or subunits may also be modified in a cell cycle-dependent manner. One such example comes from our MS analysis that detected five sites of Est 1 phosphorylation. Of these sites, three are phosphorylated in both $\mathrm{G}_{1}$ and $\mathrm{G}_{2} / \mathrm{M}$ phase cells, whereas the other two sites show cell cycle-restricted phosphorylation with one being phosphorylated only in $G_{1}$ and one only in $G_{2} / M$ phase. It remains to be seen whether these cell cycle-restricted phosphorylation events affect Est1 stability and/or telomerase activity.

\section{FUTURE PERSPECTIVES}

We are in the process of determining whether other previously unidentified proteins that copurify with telomerase 
affect its activity. We start by asking whether mutations in the associated protein affect telomere length. In addition to the studies reported here, we have identified three copurifying proteins that affect both telomere length and TLC1 abundance. We also see telomere length effects for several other genes with roles in proteolysis. Thus, the MS approach is clearly very useful for identifying telomerase regulators. Our methods are applicable to other organisms with low levels of telomerase. For example, overexpression of telomerase RNA, Est1, and Trt1 (the catalytic subunit; homolog of Est2) results in lengthening of Schizosaccharomyces pombe telomeres. By expressing both Est1 and Trt1 as fusions to GFP, we are able to use the same strategy described here to identify multiple proteins associated with fission yeast telomerase ( $\mathrm{K}$ McDonald, K-W Lin, C Webb, I Cristea, and VA Zakian, unpubl.).

\section{ACKNOWLEDGMENTS}

We thank I. Cristea, K. McDonald, A. Guise, and A. Chan for their contributions to this work and the National Institutes of Health for funding (GM43265 to V.A.Z.).

\section{REFERENCES}

Armanios M, Blackburn EH. 2013. The telomere syndromes. Nat Rev Genet 13: 693-704.

Askree SH, Yehuda T, Smolikov S, Gurevich R, Hawk J, Coker C, Krauskopf A, Kupiec M, McEachern MJ. 2004. A genomewide screen for Saccharomyces cerevisiae deletion mutants that affect telomere length. Proc Natl Acad Sci 101: 8658 8663.

Bianchi A, Negrini S, Shore D. 2004. Delivery of yeast telomerase to a DNA break depends on the recruitment functions of Cdc13 and Est1. Mol Cell 16: 139-146.

Bonetti DMM, Clerici M, Lucchini G, Longhese MP. 2009. Multiple pathways regulate $3^{\prime}$ overhang generation at $S$. cerevisiae telomeres. Mol Cell 35: 70-81.

Boule J, Vega L, Zakian V. 2005. The yeast Piflp helicase removes telomerase from DNA. Nature 438: 57-61.

Choi H, Larsen B, Lin ZY, Breitkreutz A, Mellacheruvu D, Fermin D, Qin ZS, Tyers M, Gingras AC, Nesvizhskii AI. 2011. SAINT: Probabilistic scoring of affinity purificationmass spectrometry data. Nat Methods 8: 70-73.

Cristea IM, Williams R, Chait BT, Rout MP. 2005. Fluorescent proteins as proteomic probes. Mol Cell Proteomics 4: $1933-$ 1941.

Diede SJ, Gottschling DE. 1999. Telomerase-mediated telomere addition in vivo requires DNA primase and DNA polymerases $\alpha$ and $\Delta$. Cell 99: 723-733.

Faure VCS, Hardy J, Géli V. 2010. Cdc13 and telomerase bind through different mechanisms at the lagging- and leadingstrand telomeres. Mol Cell 38: 842-852.

Ferguson JL, Chao WC, Lee E, Friedman KL. 2013. The anaphase promoting complex contributes to the degradation of the $S$. cerevisiae telomerase recruitment subunit Estlp. PLoS One 8: e55055.

Fisher T, Taggart A, Zakian V. 2004. Cell cycle-dependent regulation of yeast telomerase by Ku. Nat Struct Mol Biol 11: $1198-1205$.

Frank CJ, Hyde M, Greider CW. 2006. Regulation of telomere elongation by the cyclin-dependent kinase CDK1. Mol Cell 24: $423-432$.

Fu D, Collins K. 2007. Purification of human telomerase complexes identifies factors involved in telomerase biogenesis and telomere length regulation. Mol Cell 28: 773-785.
Gatbonton T, Imbesi M, Nelson M, Akey JM, Ruderfer DM, Kruglyak L, Simon JA, Bedalov A. 2006. Telomere length as a quantitative trait: Genome-wide survey and genetic mapping of telomere length-control genes in yeast. PLoS Genet 2: e35.

Hardy CF, Sussel L, Shore D. 1992. A RAP1-interacting protein involved in transcriptional silencing and telomere length regulation. Genes Dev 6: 801-814.

Huertas P, Sartori AA, Aguilera A, Jackson SP. 2008. CDK targets Sae2 to control DNA-end resection and homologous recombination. Nature 455: 689-692.

Jiang J, Chan H, Cash DD, Miracco EJ, Ogorzalek Loo RR, Upton HE, Cascio D, O'Brien Johnson R, Collins K, Loo JA, et al. 2015. Structure of Tetrahymena telomerase reveals previously unknown subunits, functions, and interactions. Science 350: aab4070.

Larose S, Laterreur N, Ghazal G, Gagnon J, Wellinger RJ, Elela SA. 2007. RNase III-dependent regulation of yeast telomerase. J Biol Chem 282: 4373-4381.

Larrivée MLC, Wellinger RJ. 2004. The generation of proper constitutive G-tails on yeast telomeres is dependent on the MRX complex. Genes Dev 18: 1391-1396.

Lee J, Mandell EK, Tucey TM, Morris DK, Lundblad V. 2008. The Est3 protein associates with yeast telomerase through an OB-fold domain. Nat Struct Mol Biol 15: 990997.

Lendvay TS, Morris DK, Sah J, Balasubramanian B, Lundblad V. 1996. Senescence mutants of Saccharomyces cerevisiae with a defect in telomere replication identify three additional EST genes. Genetics 144: 1399-1412.

Li S, Makovets S, Matsuguchi T, Blethrow JD, Shokat KM, Blackburn EH. 2009. Cdk1-dependent phosphorylation of Cdc13 coordinates telomere elongation during cell-cycle progression. Cell 136: 50-61.

Lin KW, Guise AJ, Chan A, Cristea IM, Zakian VA. 2015. Proteomics of yeast telomerase identified Cdc48-Np14-Ufd1 and Ufd4 as regulators of Est1 and telomere length. Nat Commun 6: 8290.

Lundblad V, Szostak JW. 1989. A mutant with a defect in telomere elongation leads to senescence in yeast. Cell 57: $633-$ 643.

Marcand S, Brevet V, Mann C, Gilson E. 2000. Cell cycle restriction of telomere elongation. Curr Biol 10: 487-490.

McGee J, Phillips J, Chan A, Sabourin M, Paeschke K, Zakian VA. 2010. Reduced Rif2 and lack of Mec1 target short telomeres for elongation rather than double-strand break repair. Nat Struct Mol Biol 17: 1438-1445.

Min B, Collins K. 2009. An RPA-related sequence-specific DNA-binding subunit of telomerase holoenzyme is required for elongation processivity and telomere maintenance. Mol Cell 36: 609-619.

Mozdy AD, Cech TR. 2006. Low abundance of telomerase in yeast: Implications for telomerase haploinsufficiency. $R N A$ 12: $1721-1737$.

Ndoja A, Cohen RE, Yao T. 2014. Ubiquitin signals proteolysisindependent stripping of transcription factors. Mol Cell 53: 893-903.

Osterhage JL, Talley JM, Friedman KL. 2006. Proteasome-dependent degradation of Est $1 \mathrm{p}$ regulates the cell cycle-restricted assembly of telomerase in Saccharomyces cerevisiae. Nat Struct Mol Biol 13: 720-728.

Sabourin M, Tuzon C, VA Z. 2007. Telomerase and Tel1p preferentially associate with short telomeres in S. cerevisiae. Mol Cell 27: 550-561.

Schuberth CRH, Rumpf S, Buchberger A. 2004. Shp1 and Ubx2 are adaptors of $\mathrm{Cdc} 48$ involved in ubiquitin-dependent protein degradation. EMBO Rep 5: 818-824.

Seto AG, Zaug AJ, Sobel SG, Wolin SL, Cech TR. 1999. Saccharomyces cerevisiae telomerase is an Sm small nuclear ribonucleoprotein particle. Nature 401: 177-180.

Seto AG, Livengood AJ, Tzfati Y, Blackburn EH, Cech TR. 2002. A bulged stem tethers Estlp to telomerase RNA in budding yeast. Genes Dev 16: 2800-2812. 
Singer MS, Gottschling DE. 1994. TLC1, the template RNA component of the Saccharomyces cerevisiae telomerase. Science 266: 404-409.

Soudet JJP, Teixeira MT. 2014. Elucidation of the DNA endreplication problem in Saccharomyces cerevisiae. Mol Cell 53: $954-964$.

Taggart AKP, Teng S-C, Zakian VA. 2002. Estlp as a cell cycle-regulated activator of telomere-bound telomerase. Science 297: 1023-1026.

Teng S-C, Chang J, McCowan B, Zakian VA. 2000. Telomeraseindependent lengthening of yeast telomeres occurs by an abrupt Rad50p-dependent, Rif-inhibited recombinational process. Mol Cell 6: 947-952.

Tuzon CT, Wu Y, Chan A, Zakian VA. 2011. The Saccharomyces cerevisiae telomerase subunit Est3 binds telomeres in a cell cycle- and Est1-dependent manner and interacts directly with Est1 in vitro. PLoS Genet 7: e1002060.

Ungar L, Yosef N, Sela Y, Sharan R, Ruppin E, Kupiec M. 2009. A genome-wide screen for essential yeast genes that affect telomere length maintenance. Nucleic Acids Res 37: 38403849.

Venteicher AS, Meng Z, Mason PJ, Veenstra TD, Artandi SE. 2008. Identification of ATPases pontin and reptin as telomerase components essential for holoenzyme assembly. Cell 132: $945-957$.

Venteicher AS, Abreu EB, Meng Z, McCann KE, Terns RM, Veenstra TD, Terns MP, Artandi SE. 2009. A human telomerase holoenzyme protein required for Cajal body localization and telomere synthesis. Science 323: 644-648.

Vodenicharov M, Wellinger RJ. 2006. DNA degradation at unprotected telomeres in yeast is regulated by the CDK1 (Cdc28/Clb) cell-cycle kinase. Mol Cell 24: 127-137.
Wan B, Tang T, Upton H, Shuai J, Zhou Y, Li S, Chen J, Brunzelle JS, Zeng Z, Collins K, et al. 2015. The Tetrahymena telomerase p75-p45-p19 subcomplex is a unique CST complex. Nat Struct Mol Biol 22: 1023-1026.

Wellinger RJ, Wolf AJ, Zakian VA. 1993. Saccharomyces telomeres acquire single-strand $\mathrm{TG}_{1-3}$ tails late in $\mathrm{S}$ phase. Cell 72: $51-60$.

Wellinger RJ, Ethier K, Labrecque P, Zakian VA. 1996. Evidence for a new step in telomere maintenance. Cell 85: $423-$ 433.

Wellinger RJ, Zakian VA. 2012. Everything you ever wanted to know about Saccharomyces cerevisiae telomeres: Beginning to end. Genetics 191: 1073-1105.

Witkin KL, Collins K. 2004. Holoenzyme proteins required for the physiological assembly and activity of telomerase. Genes Dev 18: $1107-1118$.

Witkin KL, Prathapam R, Collins K. 2007. Positive and negative regulation of Tetrahymena telomerase holoenzyme. Mol Cell Biol 27: 2074-2083.

Wotton D, Shore D. 1997. A novel Raplp-interacting factor, Rif2p, cooperates with Rif1p to regulate telomere length in Saccharomyces cerevisiae. Genes Dev 11: 748-760.

$\mathrm{Wu}$ Y, Zakian VA. 2011. The telomeric Cdc13 protein interacts directly with the telomerase subunit Est1 to bring it to telomeric DNA ends in vitro. Proc Natl Acad Sci 108: $20362-$ 20369.

Yu EY, Wang F, Lei M, Lue NF. 2008. A proposed OB-fold with a protein-interaction surface in Candida albicans telomerase protein Est3. Nat Struct Mol Biol 15: 985-989.

Zhou J, Hidaka K, Futcher B. 2000. The Est1 subunit of yeast telomerase binds the Tlc1 telomerase RNA. Mol Cell Biol 20: 1947-1955. 


\section{$\$_{\text {CSH\& }}^{\infty}$ Cold Spring Harbor Symposia SYMPOSIA}

\section{1st Century Genetics: Mass Spectrometry of Yeast Telomerase}

Kah Wai Lin and Virginia A. Zakian

Cold Spring Harb Symp Quant Biol 2015 80: 111-116 originally published online January 13, 2016

Access the most recent version at doi:10.1101/sqb.2015.80.027656

References This article cites 53 articles, 19 of which can be accessed free at: http://symposium.cshlp.org/content/80/111.full.html\#ref-list-1

\section{License}

Email Alerting Receive free email alerts when new articles cite this article - sign up in Service the box at the top right corner of the article or click here. 